Document downloaded from:

http://hdl.handle.net/10251/120922

This paper must be cited as:

Blasco Mateu, A.; Nagy, I.; Hernández, P. (2018). Genetics of growth, carcass and meat quality in rabbits. Meat Science. 145:178-185.

https://doi.org/https://doi.org/10.1016/j.meatsci.2018.06.030

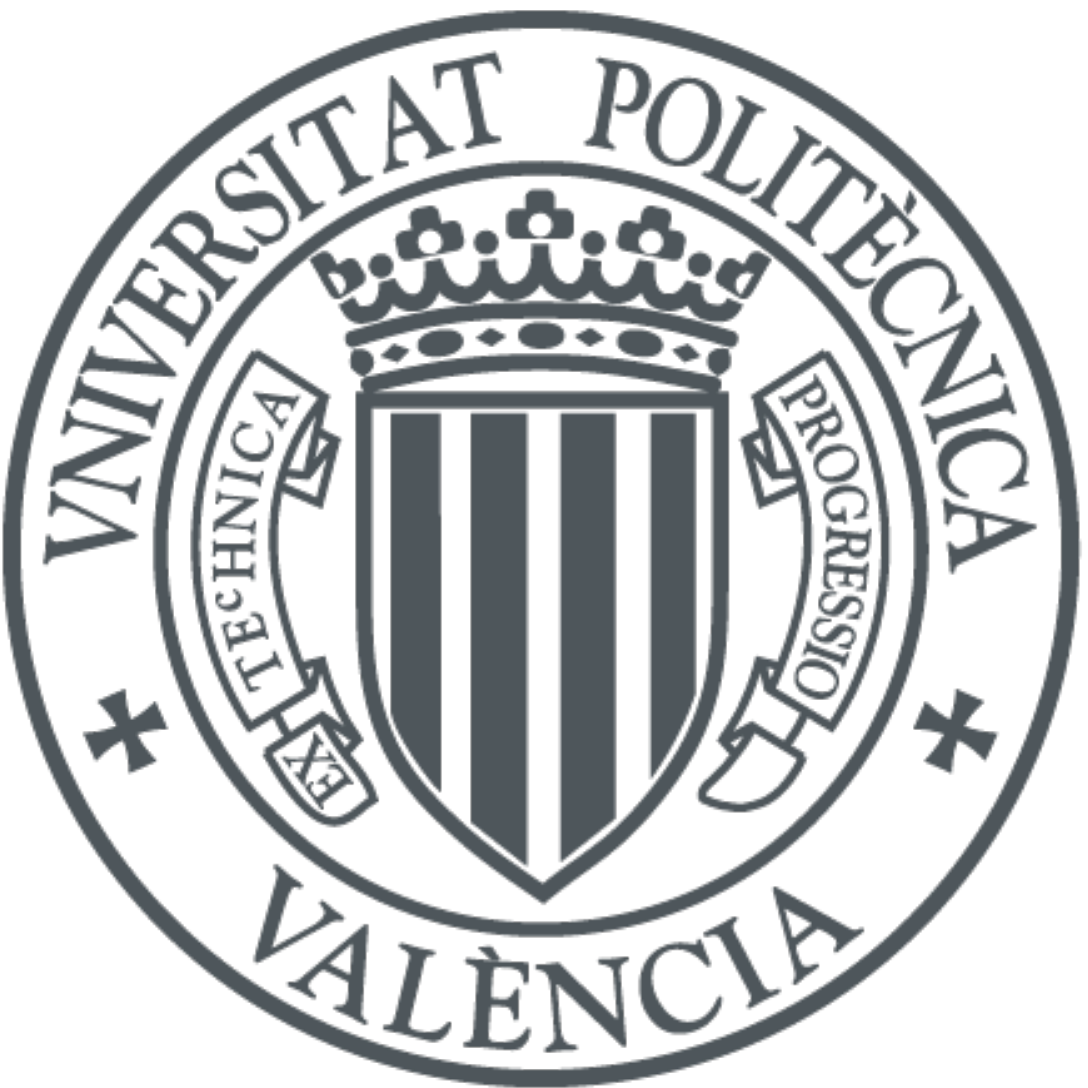

The final publication is available at

https://doi.org/10.1016/j.meatsci.2018.06.030

Copyright Elsevier

Additional Information 
4

Running head: Genetics of growth, carcass and meat quality in rabbits

\section{Genetics of growth, carcass and meat quality in rabbits}

Agustin Blasco $^{1 *}$, István Nagy² , Pilar Hernández ${ }^{1}$

${ }^{1}$ Institut for Animal Science and Technology, Universitat Politècnica de València, P.O. Box 22012. València 46071, Spain

${ }^{2}$ Department of Animal Breeding, Kaposvár University, 7400 Kaposvár, Hungary

*Corresponding author

Email addresses: ablasco@ dca.upv.es (Agustin Blasco), nagy.istvan@ke.hu (István Nagy), phernan@dca.upv.es (Pilar Hernández).

\section{Abstract}

This paper reviews the current knowledge on the genetics of growth, carcass and meat traits in rabbits. There is a great variety in size of rabbit breeds, from which commercial production uses medium size breeds for does and large breeds as terminal sires. Selection experiments for growth and feed efficiency have been successful. Selection for residual feed intake did not modify growth rate, acting on reducing the appetite. Selection for growth rate increased adult weight and led to poorer carcass yield when comparing selected and unselected animals at the same commercial weight, but not at the same age, near the same maturity stage. The results on meat/bone ratio do not show a clear pattern. Negative effects on intramuscular fat and some sensorial traits have been found in lines selected for growth rate, but meat quality in general does not seem to be affected.

Keywords: Rabbit; genetic parameters; growth traits; carcass traits; meat quality; selection 


\section{Introduction}

31 Growth is decisively important in rabbit meat production. Profit functions and economic weights of rabbit meat production have been estimated by Armero \& Blasco (1992), Prayaga \& Eady (2000) and Cartuche, Pascual, Gómez, \& Blasco (2014). Table 1 shows the costs of a typical industrial rabbitry that can be managed by one person. The main economically important traits in rabbit meat production are feed conversion rate (FCR) and litter size. This means that feed efficiency (measured as FCR, feed intake or residual feed intake) can have a decisive influence on profits. Feed conversion rate is difficult and expensive to measure, so correlated traits, such as growth rate, are often used in selection programmes with the aim of improving FCR indirectly, although genetic correlations are not as favourable as in other species. Selection programmes in rabbit commercial schemes are based on three way crosses, in which two lines are selected for litter size and crossed to produce a crossbred commercial doe, and one line is selected for average daily gain (ADG) in order to produce terminal sires (Baselga \& Blasco, 1989; Lebas, Coudert, Rochambeau, \& Thébault, 1997). This scheme is similar to what is currently used in swine. However, there are important differences, as some aspects of meat quality (e.g., PSE: Pale, Soft, Exudative meat) play an important role in swine schemes and not in rabbits, which do not present PSE meat. Moreover, selection for reducing fat content is important in pigs, but as rabbits have very lean carcasses when sold (Dalle Zotte, 2002; Hernández \& Gondret, 2006), fat content is not an important trait.

Table 1 Distribution of the costs of an industrial rabbitry with 750 reproductive does. Management in batches with A.I. Weaning at 35 days and slaughter at $2.2 \mathrm{~kg}$ of live weight (63 days). Elaborated from Cartuche et al. (2014).

\begin{tabular}{lccc}
\hline & $€ /$ doe year & $€ /$ kg live weight & $\%$ total \\
\hline Feeding rabbits for slaughter & 60.5 & 0.53 & 29.4 \\
Feeding does & 32.7 & 0.28 & 15.9 \\
Artificial insemination & 8.69 & 0.08 & 4.2 \\
Replacement reproductive stock & 11.8 & 0.10 & 5.7 \\
Health & 14.3 & 0.12 & 6.9 \\
Labour & 37.3 & 0.32 & 18.1 \\
Amortisation & 20.2 & 0.18 & 9.8 \\
Others & 20.7 & 0.19 & 10.1 \\
\hline
\end{tabular}


An important issue when comparing rabbit breeds or lines is to do the comparison at the same stage of maturity. Comparisons at the same commercial weight but a different stage of maturity can be interesting for commercial reasons, but not for finding genetic differences between groups related to carcass or meat quality. As some lines grow quicker than others do, when comparing animals at the same LW or carcass weight, rabbits of some lines are slaughtered at earlier ages, they are younger and the characteristics of the meat are different for two reasons: one is the genetic difference between lines and the other is the differences due to the age. Both effects are confounded, thus if the interest is in genetic differences between lines, they should be compared at the same stage of maturity; i.e., at the same proportion of adult body weight (BW) (Taylor, 1985). Many differences found between breeds or groups of animals under different treatments disappear or are substantially reduced when compared at the same stage of maturity. In commercial rabbit lines, if adult weight is not available, Pascual, Calle \& Blasco (2015) showed that comparisons at the same age can be used as a good approximation, but caution should be taken when comparing lines of very different size at the same age, because even at the same age, the stage of maturity can also be different (Ouhayoun \& Rouvier, 1973).

\section{Genetics of growth traits}

\subsection{Between-breed genetic variability}

Rabbits show a great variation in breed size, from dwarf (about $1 \mathrm{~kg}$ of adult weight) to giant lines (about $7 \mathrm{~kg}$ of adult weight). From the large variety of existing breeds of rabbits, commercial production uses medium size breeds for reproduction due to their high prolificacy, and large breeds as terminal sires due to their high growth rate. This also facilitates doe management and lowers the maintenance cost, allowing the production of commercial rabbits with a high growth rate.

Comparisons between breeds of very different size have not been published in standard refereed journals but are available in proceedings of congresses by Ouhayoun \& Poujardieu (1978) and by Bolet, Brun, Monnerot, Abeni, Arnal, Arnold,... \& Zimmermann (2000). Large differences in ADG (more than $15 \mathrm{~g} / \mathrm{d}$ between $4 \mathrm{wk}$ and 11 wk of age were found between breeds, as expected. An interesting result is the between-breeds negative (favourable) relationship between FCR and growth rate found by Ouhayoun \& Poujardieu 
90 Russian. This type of results has been explained by McCarthy (1980) as due to a better thermoregulation per kg of live weight (LW) of heavy breeds; maintenance energy is lower per $\mathrm{kg}$ of $\mathrm{BW}$ in giant lines because it is proportional to metabolic weight, which is a power of $\mathrm{BW}$ lower than one $\left(\mathrm{BW}^{0.75}\right.$ in the case of adult $\mathrm{BW}$. Therefore, more energy is available for growth in giant lines.

\subsection{Genetic parameters of growth traits}

There are many estimates of heritabilities of weight at a given age, typically at slaughter time (SW), which varies between countries from 9 wk (Spain) to 13 wk of age (North of Italy). There are also many heritability estimates of weaning weight (WW), daily gain (SW-WW) and ADG. Hernández \& Gondret (2006) give an average heritability for SW of 0.27 from 17 publications, ranging from 0.12 to 0.67 . Although they are widely used, average estimates of many papers are not very useful for several reasons. First, estimates may differ in quality, as some have large standard errors or are biased due to the model used or the method of estimation. Second, environmental variability can differ among farms. Third, negative estimates are not normally published or methods of estimation force estimates to be positive, producing bias in the average of estimates. Fourth, some relationships used may lead to estimates that contain non-additive variability (for example, dominance, epistasis, maternal effects, etc.). Generally speaking, estimates of heritabilities tend to be optimistic, so it is usually better to examine the estimates from selection experiments in which control populations or divergent selected populations can offer additional evidence provided by realised heritability estimates. Recently, Piles, David,

112 Ramon, Canario, Rafel, Pascual, Ragab \& Sánchez (2017) have shown that selecting

113 rabbits for daily gain under ad libitum conditions can be inefficient under restricted

114 feeding, due to competition between rabbits for feed under restricted conditions. This

115 should be taken into account when selecting for commercial rabbit farms, if they keep their 116 rabbits under a restricted feeding regime.

118 Estimates of genetic correlation between growth rate and FCR are lower than those found 119 in other species. Although they have a wide confidence interval, the three values available 120 in the literature are quite similar; Piles, Gómez, Rafel, Ramon \& Blasco (2004) give -0.49 121 (confidence interval at $95 \%$ probability [-0.94. -0.10]) and -0.47 (confidence interval at $12295 \%$ probability $[-0.99,0.13])$ for two different populations, and Drouilhet, Gilbert, 
123 Balmisse, Ruesche, Tircazes, Larzul \& Garreau (2013) give -0.38 (s.e. 0.18, which leads to an approximate confidence interval of $[-0.74,-0.02])$. As the heritability of FCR is not different from the heritability of ADG (between 0.22 and 0.31; Piles et al. (2004), Drouhillet et al. (2013)), if the true genetic correlation is around -0.4 or -0.5 , selection for growth rate would be considerably less efficient for improving FCR than direct selection for FCR.

Measures of feed efficiency other than FCR have been proposed and we discuss them in paragraph 5.2. Proposed by Koch, Swiger, Chambers \& Gregory (1963), residual feed intake (RFI) is the difference between actual feed intake and expected feed intake, according to the requirements for maintenance and growth of the animal. Residual feed intake is often estimated as the residual of a regression equation of feed intake (FI) on ADG and average metabolic weight (average LW between 30 and $63 \mathrm{~d}$ to the power 0.75 ). Residual feed intake has a low heritability (0.10 to 0.16 ) according to results of Drouilhet et al. (2013). The high value (0.45) from Larzul \& Rochambeau (2005) comes from a short divergent selection experiment (one generation) in which growth estimates of BW, ADG and RFI were all unusually high, thus their results should be taken with caution. Genetic correlation between RFI and FCR is very high (0.96, s.e. 0.03, Drouilhet et al. 2013) which means that both traits probably have a similar genetic basis. If this is the case, as the heritability of FCR is much higher, the advantage of using RFI instead of FCR in selection

143 is unclear. Piles, García-Tomas, Rafel, Ramon, Ibañez-Escriche \& Varona (2007) have

144 estimated heritabilities of the partial regression coefficients used to define RFI using

145 Bayesian techniques (Blasco 2017). Estimates of the heritability of these coefficients are

146 similar to the estimates for ADG. In paragraph 3.2, we shall discuss advantages and

147 drawbacks of the different forms of measuring feed efficiency.

\section{Genetics of carcass traits}

\subsection{Between-breed genetic variability}

153 Comparisons of different breeds and crosses show different tendencies when performed at 154 the same age (Brun \& Ouhayoun, 1989, 1994; Lukefahr, Hohenboken, Cheeke, Patton \& 155 Kennick, 1982; Metzger, Odermatt, Szendrő, Mohaupt, Romvári, Makai, ... \& Horn

156 2006a; Metzger, Odermatt, Szendrő, Mohaupt, Romvári, Makai, ... \& Sipos, 2006b; 
157 Ouyed, Rivest \& Brun, 2011; Ozimba \& Lukefahr, 1991; Szendrö, Matics, Gerencsér,

158 Radnai, Lengyel, Nagy, Riovanto \& Dalle Zotte, 2009; Szendrö, Matics, Gerencsér, Nagy,

159 Lengyel, Horn \& Dalle Zotte 2010; Rouvier, 1970) or at the same BW (Gómez, Baselga,

160 Rafel \& Ramon, 1998; Hernández, Ariño, Grimal \& Blasco, 2006; Pla, Hernández \&

161 Blasco, 1996; Pla, Guerrero, Guardia, Olivier \& Blasco, 1998).

162

163 Breeds with a lower adult BW consequently have a higher maturity at slaughter, as

164 observed by Gómez et al. (1998) Hernández et al. (2006) and Pla et al.1 996, 1998). They

165 had better dress out percentage, lower ratio of the fore part, higher ratio of the hind part

166 and greater fat depots (e.g. perirenal fat weight).

168 The number of studies evaluating the effects of heterosis based on the different crosses is

169 scarce (Brun \& Ouhayoun 1989, 1994; Ouyed et al. 2011). Although in some cases

170 favourable results were obtained for carcass yield and carcass fatness, carcass composition

171 traits were generally unaffected by individual or by maternal heterosis.

\subsection{Genetic parameters of carcass traits}

174 Due to the large samples needed to estimate genetic parameters with enough precision, the number of studies estimating the genetic parameters for carcass traits of rabbits is scarce.

176 Heritability estimates of the weight of different carcass parts are in general moderate, and

177 common litter effects are also moderate (Al-Saef, Khalil, Al-Dobaib, Al-Homidan, García

178 \& Baselga, 2008; Ferraz, Johnson \& Eler, 1991; Ferraz, Johnson \& Van Vleck, 1992),

179 (ranging between 0.29 and 0.39), but they are equal or higher than the respective

180 heritabilities of the body parts showing maternal influence for these traits. The heritability

181 estimates of carcass ratio traits have been generally higher than those for carcass parts and

182 carcass composition traits, and varied from moderate to high. The highest heritability

183 estimate was observed for fat (perirenal fat percentage), whereas muscle percentage, which

184 has much greater importance for consumers, is only moderately heritable. Thigh muscle

185 volume measured in vivo by Computer Tomography (CT) showed low heritabilities

186 (Gyovai, Nagy, Gerencsér, Metzger, Radnai \& Szendrő, 2008; Gyovai, Nagy, Gerencsér,

187 Matics, Radnai, Donkó, ... \& Szendrő, 2012; Nagy, Gyovai, Radnai, Matics, Gerencsér,

188 Donkó \& Szendrő, 2010; Nagy, Gyovai, Radnai, Nagyné Kiszlinger, Farkas \& Szendrő,

189 2013), but the average surface of the CT estimation of Longissimus dorsi et lumborum

190 (LTL) muscle had a substantially higher heritability. Using ultrasound, the heritability of 
Longissimus lumborum muscle surface (between the 2nd and 3rd lumbar vertebrae) was moderate (Lenoir \& Morien, 2015, 2016). The magnitude of maternal effects was generally low for carcass components (Krogmeier, Dzapo \& Mao, 1994) and for muscle traits measured in vivo (Gyovai et al. 2008, 2012; Nagy et al. 2010, 2013).

Dress out percentage has a moderate heritability, according to a large number of studies. However, dress out percentages of the different studies were not directly comparable, as slaughter time was different (96 vs. 63 days) (e.g. Krogmeier et al. 1994 vs. Garreau, Eady, Hurtaud \& Legarra, 2008; Larzul, Gondret, Combes \& de Rochambeau, 2005), some studies did not follow the WRSA recommendations (Blasco, Ouhayoun \& Masoero, 1993; Blasco \& Ouhayoun, 1996) for dissection, distal parts of the legs were not removed (Rouvier 1970) or carcasses did not include the head (Ferraz et al. 1992; Lukefahr, Odi \& Atakora, 1996). Moreover, several authors (Al-Saef et al. 2008; Ferraz et al. 1992; Krogmeier et al. 1994) used hot carcass weight for calculating dress out percentage instead of cold carcass weight. There is only one experiment reporting different heritabilities for different colour values, ranging from $0.11 \mathrm{of}^{*}$ (yellowness) to 0.36 of $\mathrm{a}^{*}$ (redness) (Martínez-Álvaro, Hernández \& Blasco A. 2016a).

Sample size of carcass studies is limited due to its cost. As large samples are needed to estimate genetic correlations with precision, estimates of the published experiments have large standard errors and should be taken with caution. The available literature is limited to only a few publications. Garreau et al. (2008) and Krogmeier et al. (1994) did not find a genetic correlation between dress out percentage and perirenal fat percentage. Nagy, Ibañez, Mekkawy, Metzger, Horn \& Szendrő (2006) have published some genetic correlations based on CT scans, observing a negative genetic correlation between muscle

216 LTL volume and perirenal fat weight and a moderately high genetic correlation between

217 the average cross sectional area of the LTL muscle and dress out percentage. This latter

218 finding was corroborated by Lenoir \& Morien (2015) using ultrasound technique. Thigh muscle volume showed a null genetic correlation with dress out percentage and a moderately strong correlation with hind part percentage (Nagy et al., 2010). Consequently, selection for thigh muscle volume by CT might also improve hind part percentage.

\section{Genetics of rabbit meat quality}


Meat quality depends on many traits affected by different metabolic pathways. Hitherto no single genes affecting rabbit meat quality have been discovered, thus the genetic determination of meat quality in rabbits is multi-trait and seemingly multifactorial. Meat quality is measured after slaughter and the traits measured are often difficult and expensive to record. These difficulties, plus the fact of having neither a single measure nor a single gene to concentrate the efforts to improve meat quality, prevent the inclusion of meat quality in selection programmes. Nevertheless, the consequences on meat quality of current selection programmes for growth should be examined.

\subsection{Genetic variability between rabbit lines}

235 Differences between lines or crosses have been found for several meat traits. These 236 differences may be due to differences in the genetic composition of the lines compared.

237 However, in meat quality studies, the sample size is small because traits are difficult and 238 expensive to record, which often leads to non-significant differences that could be relevant. 239 For example, small sample sizes sometimes do not allow us to draw conclusions when 240 comparing lines. For both reasons, variability in the genetic composition of the lines compared and small sample size, the comparison between lines is not very informative and often helps only as a first indication about the variability that can be found for certain characteristics. Given the great variability in size among rabbit lines, some studies have associated differences in some meat characteristics to differences in line size. Hulot \& Ouhayoun (1999) reviewed the literature on breed differences in meat $\mathrm{pH}$, finding substantial differences between lines or crosses (roughly one standard deviation of the trait). In general, no association between breed size and meat $\mathrm{pH}$ can be inferred, as no clear pattern appears. Blasco \& Piles (1990) did not find any correlation within lines between carcass weight and meat $\mathrm{pH}$.

250 Differences in meat colour values $\left(\mathrm{L}^{*} \mathrm{a} * \mathrm{~b} *\right)$ have also been found by Bernardini Battaglini, 251 Castellini \& Lattaioli (1995), Hernández et al. (2006) and Dalle Zotte, Szendrő, Gerencsér, 252 Szendrö, Cullere, Odermatt, ..., \& Matics (2015) in lines of different sizes, but without a 253 clear pattern either. No differences in water holding capacity (WHC) were found by

254 Bernardini Battaglini et al. (1995) and Ariño, Hernández \& Blasco (2006) when comparing lines of different size.

257 Differences in meat texture between synthetic giant and medium lines were reported by

258 Lukefahr et al. (1982) and by Ariño et al. (2006). In both cases, the heavy lines were more 
tender, and in the study of Ariño et al. (2006), the heavier line had higher proteolytic activity and lower collagen content. Ariño, Hernández, Pla \& Blasco (2007) also performed a sensory analysis, finding differences in tenderness in the same direction, but no differences in flavour or odour traits were found.

Using the same lines, Ramírez, Díaz, Pla, Gil, Blasco \& Oliver (2005) and Hernández, Cesari \& Blasco (2008) compared lipid content and fatty acid composition of rabbit hind leg meat and perirenal fat. They found no differences in MUFA, but lower SFA and higher PUFA percentages in one of the lines selected for litter size; the differences were substantial, more than one standard deviation of the indices. Other authors (Gasperlin, Polak, Rajar, Skvarea \& Lender, 2006) found no differences in SFA, MUFA and PUFA between a local breed and a commercial breed, but their experiment had a small number of animals and s.e. were high. Hernández et al. (2008) also found differences in lipolytic activities between a line selected for growth rate and lines selected for litter size, but free FA after refrigerated storage were not influenced by rabbit line. No differences were found either for the enzyme activity of the muscle energy metabolism, such as aldolase and ICDH, or for oxidative parameters (Hernández et al. 2006).

\subsection{Genetic parameters of meat quality traits in rabbits}

278 The only meat quality traits for which reliable estimates of heritability have been published are muscular $\mathrm{pH}$, colour, intramuscular fat, meat FA profile and instrumental texture. Larzul et al. (2005) gave a heritability estimate of 0.16 for ultimate $\mathrm{pH}(\mathrm{pHu})$, but its s.e. was high (0.09) and it was not different from zero. A similar result, 0.08 with a $95 \%$ confidence interval of $[0.01,0.20]$ was found by Martinez-Alvaro et al. (2016a). However, Larzul \& Rochambeau (2005) gave a heritability of 0.50 (s.e. 0.16); despite its large confidence interval, this result suggests that selection might be possible on $\mathrm{pHu}$. Carcass colour $(\mathrm{L} * \mathrm{a} * \mathrm{~b} *)$ shows conflicting results, with heritabilities near zero (Larzul \& Rochambeau, 2005; Larzul et al. 2005), or between 0.14 and 0.25 (Martinez-Alvaro et al. 2016a). The latter result is consistent with the correlated response to selection found in an experiment by Hernández, Aliaga, Pla \& Blasco (2004) that we shall see in paragraph 5.3. A Bayesian estimate of heritability (Blasco 2017) of intramuscular fat (IMF) was provided by Martinez-Alvaro et al. (2016a). The estimate was 0.54 , with a probability of $95 \%$ of being higher than 0.40 , and this high heritability was corroborated by results of a selection 
were positive but relatively low (0.3), of the same order as the correlation between IMF and reference carcass weight, meat/bone ratio and pHu (Martinez-Alvaro et al. 2016a).

295 This is an interesting result, showing that an increment in meat quality increasing IMF is not necessarily accompanied by a rapid impairment of carcass quality incrementing fat depots. A single study estimating heritabilities of fat composition (Martinez-Alvaro et al. 2016a) shows low heritability (0.09) for SFA, and high heritabilities for MUFA (0.61) and PUFA (0.45), as well as for the PUFA:SFA ratio (0.42). Genetic correlations between IMF and meat FA percentages were strong and positive for MUFA, with a strong and negative PUFA and PUFA:SFA ratio. Correlation between IMF and SFA was positive, but the estimate had a wide confidence interval. Martinez-Alvaro et al. (2018c) also found high heritabilities for percentages of individual FA C14:0, C18:0, C16:1, C18:1n-9, C18:2n-6 and C20:4n-6. High positive genetic correlations were found between IMF and C14:0, C16:1, C18:1n-9 and strong negative correlations for C18:0, C18:2n-6, and C20:4n-6. All these estimates were corroborated by observed correlated responses to selection, described in section 5.5. Instrumental texture (Warner-Bratzler shear force; WBSF) showed a high heritability, 0.57 (Larzul et al. 2005), with a rather surprising low s.e. (0.02). Genetic correlations between growth rate and $\mathrm{pHu}$, and growth rate and WBSF, were not different from zero. The former correlation agrees with the null correlated response in $\mathrm{pH}$ obtained in selection experiments for growth rate, but the correlation between WBSF and growth rate was not confirmed by selection experiments, as described in paragraph 5.3.

\section{Selection experiments}

316 A common problem when evaluating selection experiments is the lack of a control

317 population for estimating the response to selection. When a control is not available, mixed 318 model techniques allow us to estimate this response, but the estimate is heavily dependent

319 on the estimates of genetic parameters used in the model. If these parameters are estimated 320 with the same set of data or in the same population, a better estimate of the response is obtained. However, experience shows that heritabilities are often overestimated due to biases from ignoring non-additive variability or part of the environmental variance. For example, it is well known that the litter size estimates of heritabilities are around 0.10 and that the responses of selection experiments are much lower than expected. Divergent selection experiments allow us to use each population as control of the other, but symmetry in the response is not guaranteed and, consequently, biased estimates of response may 
result. A control population gives a set of data not affected by selection and provides the means to obtain an unbiased estimate of response although, due to limitations in experimental facilities, it is less accurate than those obtained using mixed model methodology. We consider selection experiments for growth, feed efficiency and meat quality in this review.

\subsection{Selection for growth}

Only published experiments on selection for growth rate are hereafter considered, whereas multipurpose lines or lines selected for other traits are not contemplated. Responses to selection for growth rate have been reported by Rochambeau, de la Fuente, Rouvier \& Ouhayoun (1989), Lukefahr et al. (1996), Piles \& Blasco (2003) and Larzul et al. (2005) with a control population, and two divergent selection experiments were performed by Moura, Kaps, Vogt \& Lamberson (1997). Recently, an experiment of selection for ADG under restricted feed consumption was carried out by Drouilhet et al. (2013) and Drouilhet, Achard, Zemb, Molette, Gidenne, Larzul, .. \& \& Gilbert (2016), as nowadays in intensive farming conditions the rabbits are generally under restricted feeding regimes to prevent digestive disorders after weaning. Other studies have a less clear interpretation (Rochambeau, Retailleau, Poivey \& Allain, 1994; Ferraz et al. 1992), or an arguable methodology (Niedzwiadek, Fijal \& Bielanski, 1992).

In all these experiments, the selection was successful. In those with a control population, Rochambeau et al. (1989), selecting for ADG between 30 and 77 days of age, obtained a response per generation of $0.83 \mathrm{~g} / \mathrm{d}$ in eight generations of selection, which represents a progress of $2 \%$ of the mean per generation. Piles \& Blasco (2003) obtained lesser progress, $0.56 \mathrm{~g} / \mathrm{d}$ per generation in seven generations of selection, $1.2 \%$ of their mean per generation. In both experiments a correlated response was observed in slaughter weight (SW) (77 and 63 days of age, respectively), but not in weaning weight (WW). This is expected, as weight gain after weaning is a large part of SW. Lukefahr et al. (1996) directly selected by LW at 70 days, obtaining a correlated response in five generations of selection of $2.7 \mathrm{~g} / \mathrm{d}$ from 28 to 70 days of age, which represents $1.4 \%$ of the mean per generation. Larzul et al. (2005) selected for LW at 63 days in a divergent selection experiment, also with a control population. The difference between high and low lines for ADG between 28 and 63 days of age after five generations of selection was $12 \mathrm{~g} / \mathrm{d}$, the control population being intermediate between both values. As response was symmetrical, 
361 the correlated response per generation in ADG was $6 \mathrm{~g} / \mathrm{d}$ in five generations, $1.2 \%$ per

362 generation. The divergent selection experiment for ADG of Moura et al. (1997) gives a

363 difference between high and low line of $8.4 \mathrm{~g} / \mathrm{d}$ from 56-60 days to 84-88 days of age,

364 which means $4.5 \%$ of the mean per generation, or $2.25 \%$ per generation if the response was

365 symmetrical. However, it appears that Moura et al. (1997) had greater success in

366 decreasing daily gain than in increasing it. Under restricted feeding, selection for ADG led

367 to a response of $1.9 \mathrm{~g} /$ day after nine generations of selection, corresponding to $0.5 \%$ of the

368 mean of this trait per generation (Garreau, Gilbert, Molette, Larzul, Balmisse, Ruesche, ...

369 \& Drouilhet, 2015a; Garreau, Gilbert, Molette, Larzul, Balmisse, Ruesche \& Secula-

370 Tircazes, 2016), lower than the response found in experiments without restriction. This

371 was expected, as the full potential for growth is not necessarily expressed under restriction.

372 Restricted feeding had an important effect on ADG, and the authors found a difference of

$37311.2 \mathrm{~g} / \mathrm{d}$ between restricted and ad libitum feeding in their lines.

375 It is important to note that observed responses were in all cases lower than the expected responses based on previous heritability estimates of ADG or LW. However, as rabbit generation interval for growth rate selection can be very small (six months), the responses would be between 2 and $4 \%$ of the mean per year, which are good results compared with other domestic species (Smith, 1984).

\subsection{Selection for feed efficiency}

382 Several traits measuring feed efficiency can be found in the literature. The most common

383 one is FCR, the ratio between feed intake (FI) and body weight gain (BWG) in a fixed

384 range of days. Recently, RFI has been widely used in several animal species. Both

385 measurements have advantages and disadvantages. A good FCR can be obtained by

386 reducing FI at a given weight, or augmenting LW for a given amount of FI. Selection for

387 FCR acts mainly on the most variable trait, the numerator, and tends to reduce

388 consumption without increasing BWT. This has been observed in growing pigs (see

389 review by Webb 1989), and later in sows (see review by Prunier, Heinonen \& Quesnel,

390 2010), which may create some problems in the future when nutrition demands for

391 maintaining higher litter size will increase. Another issue is that the correlation between

392 FCR and LW or ADG gives rise to the so-called "spurious correlations" (Pearson, 1897),

393 as FCR includes LW in the denominator. Whereas this can be taken into account for

394 interpreting results, it is irrelevant for its inclusion in a selection index, in which 
correlations are considered to obtain the maximum profit, independently of how they are generated. On the other hand, RFI has also received criticisms. As Kennedy, Van der Werf \& Meuwissen (1993) demonstrated, using RFI in a selection index instead of FCR does not add any new information to the index. If RFI is directly selected without its inclusion in an index, profits will be lower, as the component traits are not weighted to obtain the maximum benefit, as the index does. Besides, we have seen before that RFI in the rabbit seems to have a genetic correlation with FCR close to one but a lower heritability, so its use in selection would be less efficient for improving feed efficiency than measuring FCR directly. Moreover, RFI is not a residual, but an estimate of a residual; this means that the error of estimation and the correlations between estimated residuals are not considered (residuals are uncorrelated, but the estimates of residuals are not). A further criticism is that metabolic weight, when used in the definition of RFI, is estimated as BW to the power of 0.75 , which is right for adult animals, but metabolic weight in growing animals can have quite different powers, being about 1.0 -i.e., directly proportional to weight - during growth (Brody 1945, pp. 448-449; Taylor 2009). Selection index for ADG and FI or FCR using appropriate economic weights should be the method giving the highest expected profit. However, selection indexes are sensitive to errors in the estimation of genetic parameters, which can lead to lower profits than expected. If so, selection for FCR or RFI may produce better results.

415 Experiments on feed efficiency in rabbits have been performed selecting for FCR (Moura et al. 1997), RFI (Larzul \& Rochambeau, 2005; Drouhillet et al. 2013, 2016) and ADG under restricted feeding (Drouillet et al. 2013, 2016). The divergent selection experiment of Moura et al. (1997) reports inconsistent results for the differences between lines, with the high line having a lower FCR than the low line at the end of the experiment. However, using mixed model techniques they found a symmetric progress of $0.6 \%$ per generation in each direction for FCR in the period ranging from 56-60 days to 84-88 days of age. The divergent selection experiment on RFI carried out by Larzul \& Rochambeau (2005) was too short to drive conclusions; they only had one generation of selection and their results comparing high and low lines were not significant, therefore nothing can be said about whether selection on RFI was successful or not. A longer experiment was carried out on RFI between 30 and $65 \mathrm{~d}$ of age by Drouilhet et al. (2013, 2016), showing remarkably similar results when using a control population or analysing the whole experiment by using mixed model techniques. After nine generations of selection, they found a response 
of -39 $\mathrm{g}$ of RFI per generation, and a correlated response of -0.20 in FCR, corresponding

430 to decreases of $0.9 \%$ and $0.8 \%$ per generation, respectively (Garreau et al. 2015a, 2016).

431 No correlated response was found for growth rate, showing that selection acted upon

432 reducing appetite.

433

\subsection{Consequences of selection for growth rate or feed efficiency}

435 Selection experiments have been successful, and the cumulative progress per year allows us to increase growth rate substantially in a few years' time. This has several consequences, which we shall subsequently examine:

\subsubsection{Changes in adult weight}

440 As Taylor (1985) stressed, all BW are genetically correlated and selection for growth rate should lead to an increase in adult weight. This was shown in rabbits by Blasco et al .

442 (2003) fitting growth curves to a line selected by growth rate and to a control population.

443 Adult weight increased by $1 \%$ per generation, near the progress obtained in growth rate.

444 Taylor (1980) suggested comparing growth curves by representing them in a metabolic 445 scale in which the axes would be stage of maturity (i.e., weight divided by adult weight) 446 from 0 to $100 \%$, and metabolic time. This metabolic time comes from the observation by 447 Taylor (1965) that time to reach maturity is proportional to metabolic adult weight (Taylor 448 estimates metabolic adult weight as adult weight to the power of 0.73 ), thus 'metabolic 449 time' is actual time divided by metabolic adult weight. When curves of the selected and 450 control populations were represented in Taylor's metabolic scale, the effect of selection 451 disappeared, showing that selection did not change the shape of the curve (Blasco, Piles \& 452 Varona, 2003) and that adult weight increased due to a scale effect. In consequence, lines 453 selected for growth rate would become giant lines, more expensive to maintain and 454 manage. Nevertheless, in modern industrial rabbit production this should not be a serious 455 problem, as artificial insemination is widely used and very few terminal sires are needed.

\subsubsection{Changes in FCR}

458 As SW is determined by the market, lines selected for growth rate are slaughtered at 459 earlier ages, saving on feeding costs. This is the main cause of the improvement in FCR.

460 When compared at the same age, the selected line will have a higher LW and consequently 461 a better use of energy for maintenance, as the losses are proportional to a power of BW 462 lower than 1 (0.75 for adult weight). Larzul et al. (2005) did not find differences in FCR 
463 between a line selected for ADG and the control line after five generations of selection.

464 The only direct evidence of FCR improvement through selection on ADG comes from the three generations of the selection experiment of Moura et al. (1997), showing consistently lower values for FCR in the line selected to increase ADG, and a progress around $3.5 \%$ of the mean of the trait per generation in each direction. However, the line selected for FCR did not show appreciable changes in ADG, so no straightforward conclusions can be drawn from the experiment. Consequences of selection for growth rate on feed efficiency can also be drawn from estimated genetic parameters. Unfortunately, many data items (at least a few thousand) are needed to estimate genetic correlations with reasonable accuracy, and this is not feasible for traits like individual FCR that are expensive to measure. Under restricted feeding, Garreau, Molette, Gilbert, Larzul \& Balmisse (2015b) found a correlated response in FCR of -0.19 , corresponding to $0.8 \%$ of the mean per generation, a remarkably similar result to the response for FCR in their line selected for RFI quoted previously (Garreau et al. 2015a). As the crucial trait in rabbit meat production is FCR (Cartuche et al. 2014) and both lines had almost the same response to selection for this trait, selection for growth rate under restricted feeding seems easier to implement in a genetic programme. This will produce heavier animals in the long term (Garreau et al. 2015a, Drouilhet et al. 2016) but if the commercial slaughter weight remains the same, the only consequence would be that rabbits will be slaughtered earlier.

\subsubsection{Changes in carcass quality}

Rabbits selected for growth rate are slaughtered at the same commercial weight as unselected rabbits, thus they are slaughtered at earlier ages and are younger than rabbits that were not selected for growth rate. Slaughtering younger animals implies a poorer carcass yield, a slightly higher bone ratio and a slightly different proportion of retail cuts. A lower fat content is also expected, as fat is a tissue of late deposition; however, selection for growth rate increases appetite, and it is well known in other species that an increment of daily FI can lead to fat deposition independently of age (Whittemore, 1987). The effect of selection for growth rate at fixed BW has been estimated by Gondret, Larzul, Combes \& de Rochambeau H (2005) and Pascual \& Pla (2007). Both studies found a higher dissectible fat percentage of the carcass and a lower meat/bone ratio in the hind leg of the line selected for increased ADG, and Gondret et al. (2005) found a poorer carcass yield in this line, as expected. As rabbits were slaughtered at a different maturity stage, there is confounding between the actual effect of selection and the effect of maturity. 
498 Because retail cuts and tissue composition are highly correlated to $\mathrm{BW}$, large differences are not expected when comparing at the same stage of maturity, as growth curves are

500 almost coincident when they are expressed in metabolic scale. Pascual, Pla \& Blasco 501 (2008) have examined the effect of selection for growth rate on the relative growth of 502 carcass tissues and retail cuts. They compared allometric coefficients of retail cuts of the

503 line selected for growth rate by Piles \& Blasco (2003) and a control population, and 504 compared hind leg meat and bone tissues. After 11 generations of selection, no effect of 505 selection on the relative growth of any of the components studied was found. The effect of selection for growth rate on carcass composition at the same age has been examined by Lukefahr et al. (1996), Hernández et al. (2004) and Larzul et al. (2005), and by Garreau et al. (2015b) under restricted feeding conditions. Lukefahr et al. (1996) and Hernández et al. (2004) did not find differences between selected and control group in carcass yield, although Larzul et al. (2005) found a small difference in favour of the selected line for high ADG. Hernández et al. (2004) found less fat in the line selected for ADG than in the control line, a result also found in former analysis of the same line (Piles, Blasco \& Pla, 2000), which is not in agreement with results found by Larzul et al. (2005), who observed more dissectible fat in the high than in the low line. The norms of the World Rabbit

515 Science Association (Blasco \& Ouhayoun, 1996) recommend using the meat and bones of 516 the hind leg for comparisons, as it is more closely related to the meat, bone and meat/bone ratio of the whole carcass. Lukefahr et al. (1996) only considered the loin cut, finding no differences between groups, but some advantage for the selected line in muscle/bone ratio of this retail cut. Differences in meat/bone ratio of the hind leg were found by Gondret et al. (2005) in their divergent selection experiment for ADG, where the low line had a better ratio than the control, although no differences were found between the control and the high

522 line; conversely, Hernández et al. (2004) observed a higher meat/bone ratio in the line selected for ADG. As a general pattern, no differences were found by Hernández et al. (2004) between selected and control lines in retail cuts and other parts of the carcass (head, kidneys, liver, lungs and heart). In the study of selection for growth rate under restricted feeding conditions (Drouilhet et al. 2013, 2016), a substantial correlated response in perirenal fat was found (19\% reduction in 9 generations of selection, $2 \%$ of the mean of the trait per generation), although no response in scapular fat occurred. No correlated responses in hind leg, intermediate part of the carcass, meat/bone ratio and carcass yield were found. Their line selected for RFI had an even higher correlated 
531 response in perirenal fat (33\% in 9 generations of selection, $3.6 \%$ of the mean of the trait

532 per generation), and a substantial response in scapular fat ( $2 \%$ of the mean per generation).

533 Favourable correlated responses in hind leg proportion and meat/bone ratio were also

534 obtained in this line.

535

\subsubsection{Changes in meat quality}

537 Changes in meat quality due to selection for growth rate have been investigated by

538 Hernández et al. (2004) (study 1), and in a divergent selection experiment by Larzul et al.

539 (2005) (study 2), with both experiments using control populations. There are many traits

540 related to meat quality and it is not always easy to summarise them or to find a single way

541 to characterise meat. Among the most important meat quality traits are $\mathrm{L}^{*} \mathrm{a} \mathrm{b}^{*}$ colour and

$542 \mathrm{pHu}$. Differences in colour between selected and control lines in LTL meat were found in

543 study 1. In rabbits, usually sold as whole carcass or as retail cuts, the colour of the carcass

544 can be considered a quality trait more closely related to consumer preferences than meat

545 quality. Hernández et al. (2004) found that the selected line had higher L*, and lower a*

546 and $b^{*}$ values than the control line, whereas in study 2 no differences were observed

547 between selected and control lines. The pHu was measured in the m. LTL in study 1

548 (Ramírez, Oliver, Pla, Guerrero, Ariño, Blasco, Pascual \& Gil 2004) and in m.

549 Semitendinosus and m. LTL in study 2 (Larzul et al. 2005), and no differences were

550 observed between selected and control lines. As for WHC, it was lower in the selected line

551 of study 1, a difference that was also observed for cooked meat in previous analyses with

552 the same lines, although in cooked meat the evidence was less strong (Piles et al., 2000).

553 There is some evidence in study 1 of selection for growth rate increasing the percentage of

554 fat content in the meat of the hind leg, as well as changes in FA composition. However,

555 changes in indices related to human health were very small, the strongest effect being for

556 the PUFA/SFA ratio, which only decreased from 1.06 to 0.95 in 14 generations of

557 selection (Ramírez et al. 2005). Selection for growth rate changed meat toughness in both

558 experiments (study 1: Ramírez et al. 2004; study 2: Larzul et al. 2005, study 2), but it

559 affected texture parameters without a clear pattern. Nevertheless, no difference in

560 tenderness, juiciness or fibrousness was detected by a trained panel test in study 1 .

561 Moreover, muscle fibre analyses, more related to the myofibrillar tenderness, showed no

562 differences in fibre typing and diameter between the line selected for increasing growth

563 rate and the control line (study 2). Selection for growth rate had a negative effect on some

564 sensory traits, as it increased liver flavour and decreased aniseed odour and flavour (study 
566 traits related to meat quality analyses were also investigated: proteolytic enzyme activities

567 (calpains and cathepsins activities and cysteine proteinase inhibitors) and lipolytic enzyme activities in study 1 showed no effect of selection for growth rate (Gil, Ramírez, Pla, Ariño, Hernández, Pascual, ... \& Oliver, 2006). When selecting for growth rate under restricted feeding (see section 5.2), no change of WHC in cooked meat was observed, but some differences in pHu and L* emerged (Molette, Gilbert, Larzul, Balmisse, Ruesche, Manse, ... \& Drouilhet 2016). Minor unfavourable changes in the latter traits were found for their line selected for RFI.

575 The general picture is that selection for growth rate does not clearly affect meat quality, with the experiments showing some small changes, not always in the same direction, which may be attributed to genetic drift or sampling error.

\subsection{Selection for increasing muscle volume}

580 Based on CT scanning of live rabbits, two divergent selection experiments were performed. In the first experiment (Szendrö, Romvári, Horn, Radnai, Bíró-Németh \& Milisits, 1996), male rabbits were selected for the average surface of the m. Longissimus lumborum (between the $2^{\text {nd }}$ and $3^{\text {rd }}$ and $4^{\text {th }}$ and $5^{\text {th }}$ lumbar vertebra), and the experiment lasted two and three generations for the low and high lines, respectively. In the second experiment, both males and females were selected (Szendrő, Metzger, Nagy, Szabó, Petrási, Donkó \& Horn, 2012), for increasing thigh muscle volume and the trial lasted three generations. The selection experiments were both successful. In the first experiment (Szendrö et al. 1996), for the average surface of the m. Longissimus lumborum a difference of $1.3 \mathrm{~cm}^{2}$ was observed between the high and low lines, and a correlated response of $2 \%$ for dress out percentage. The intermediate and hind parts of the rabbit carcass differed by 22 and $14 \mathrm{~g}$, respectively, whereas the gastrointestinal tract had a $23 \mathrm{~g}$ difference between

592 high and low lines. Similar results were reported in the second experiment (Szendrö et al., 593 2012), where the difference between the thigh muscle volumes between the high and low 594 lines was $25 \mathrm{~cm}^{3}$; moreover, the high line had lower FI (128 vs $138 \mathrm{~g} / \mathrm{d}$ ) and better FCR 595 (2.81 vs 3.01). Percentages of the fore part (30.1 vs 29.4\%), perirenal fat (2.40 vs $1.90 \%$ ) and scapular fat (1.07 vs $0.49 \%$ ) of the reference carcass were higher in the low line,

597 whereas ratios of the hind part (36.3 vs 38.2\%) and meat of both hind legs (26.9 vs. 28.7\%)

598 were higher in the high line. Therefore, CT-aided selection can improve muscle volume 
and other carcass traits. The main results of the breeding programme based on CT-aided

600 selection were summarised by Matics, Nagy, Gerencsér, Radnai, Gyovai, Donkó, ... \&

601 Szendrő (2014).

602

603

\subsection{Selection for intramuscular fat content}

604 Intramuscular fat (IMF) is a main meat quality factor, affecting sensory properties and 605 related to the nutritional value of the meat. A divergent selection experiment on IMF of 606 rabbits was carried out by Zomeño, Hernández \& Blasco (2013a, 2013b), Martinez-Alvaro 607 et al. (2016a) and Martínez-Álvaro, Penalba, Hernández \& Blasco (2016b), evaluating 608 candidates for selection with the IMF of muscle Longissimus dorsi from two sibs. After seven generations of divergent selection, they obtained a divergence around $5 \%$ of the mean $(1.09 \mathrm{~g} / 100 \mathrm{~g})$ per generation, with both lines following a symmetrical trend

611 (Martinez-Alvaro et al. 2016a). Positively correlated responses to IMF selection were

612 found in Biceps femoris, Supraspinatus and Semimembranosus proprius muscles

613 (Martínez-Álvaro, Hernández, Agha \& Blasco, 2018a). No correlated responses were

614 found for $\mathrm{pHu}$ in any muscle. Colour traits of the carcass and of the meat were not affected

615 by selection, (Martinez-Alvaro et al. 2016a). Greater lipogenic activities in muscles

616 Semimembranosus proprius and LTL, perirenal fat and liver were observed in the high line

617 than in the low line (Martínez-Álvaro, Blasco \& Hernández, 2017; Martínez-Álvaro,

618 Paucar, Satué, Blasco \& Hernández, 2018b). There was a correlated response in perirenal

619 fat content, which was greater in the high line. Correlated responses were found in meat

620 FA percentages. The low line had greater PUFA and lower MUFA than the high line,

621 whereas SFA was similar in both lines (Martinez-Alvaro et al. 2016a), leading to

622 unfavourable values for PUFA/SFA and favourable MUFA/SFA ratios in the high line. In 623 general, individual FA of the MUFA and PUFA groups showed a similar pattern, with the

624 exception of C18:3n-3 percentage, which was greater in the high line. (Martínez-Álvaro et 625 al. 2017). The same pattern was found in other muscles (Martínez-Álvaro, Blasco \& 626 Hernández, 2018c). The increase of dissectible fat and the worsening in PUFA/SFA ratio 627 means that selection for IMF can deteriorate carcass and meat quality from a nutritional 628 point of view. However, the amount of dissectible fat in rabbit carcasses $(2.5 \%$ at 9 wk and $6293.5 \%$ at 13 wk, Hernández et al. 2004) and the percentage of IMF are so low in rabbits 630 (about 1\%, Zomeño et al. 2013a) that differences due to selection would not compromise 631 human health when consuming rabbit meat. Finally, WBSF toughness was $9.9 \%$ greater in 632 the low line than in the high line, whereas other instrumental texture and sensory attributes, 
633 and cooking loss, were similar in both lines. No effect of selection for IMF was observed

634 in any sensory attributes (Martinez-Alvaro et al. 2016b).

635

636

\section{Conclusion}

637 Rabbit meat is an industrial product in which feed efficiency plays a key economic role.

638 Feed efficiency is indirectly improved by selection on growth rate, although the genetic

639 correlation in rabbit is lower than in other species. Selection for growth rate and feed

640 efficiency has been successful, although feed efficiency selection is restricted to

641 experiments due to the high cost of measuring feed consumption. Selection has

642 consequences in carcass and meat quality, as rabbits are slaughtered at fixed commercial

643 weight, so slaughtering younger animals entails poorer carcass yield, slightly higher bone

644 ratio and slightly different proportions of retail cuts. It seems that it is possible to select for

645 muscle volume by computer tomography, and for some traits related to meat quality such

646 as intramuscular fat but, as with feed efficiency, this selection is difficult to apply at

647 industrial level due to the high cost involved in measuring these traits. Meat quality is not

648 paid for nowadays in rabbit meat markets, and it seems that selection for growth rate is not

649 seriously affecting rabbit meat quality, but it is advisable to monitor changes due to

650 selection for growth rate.

651

652

653 References

654

655

Al-Saef, A.M., Khalil, M.H., Al-Dobaib, S.N., Al-Homidan, A.H., García, M.L., \&

656

657

658

659

660

661

662

Arino, B., Hernández, P., Pla M., \& Blasco, A. (2007). Comparison between rabbit lines

663 for sensory meat quality. Meat Science, 75, 494-498.

664 Armero, Q., \& Blasco, A. (1992). Economic weights for rabbit selection indices. Journal 665 of Applied Rabbit Research, 15, 637-642. 
666

667

668

669

670

671

672

673

674

675

676

677

678

679

680

681

682

683

684

685

686

687

688

689

690

691

692

693

694

695

696

697

698

Baselga, M., \& Blasco, A. (1989). Mejora genética del conejo de producción de carne. Mundi-Prensa. Madrid.

Bernardini Battaglini, M., Castellini, C., \& Lattaioli, P. (1995). Effect of sire strain, feeding, age and sex on rabbit carcass. World Rabbit Science, 3, 9-14.

Blasco, A. (2017) Bayesian data analysis for animal scientists. New York: Springer.

Blasco, A., \& Piles M. (1990). Muscular pH of the rabbit. Annales de Zootechnie, 39: 133136.

Blasco, A., Ouhayoun, J., \& Masoero, G. (1993). Harmonization of criteria and terminology in rabbit meat research. World Rabbit Science, 1, 3-10.

Blasco, A., \& Ouhayoun, J. (1996). Harmonization of criteria and terminology in rabbit meat research. Revised proposal. World Rabbit Science, 4, 93-99.

Blasco, A., Piles, M., \& Varona, L. (2003). A Bayesian analysis of the effect of selection for growth rate on growth curves in rabbits. Genetics Selection Evolution, 35, 21-42.

Bolet, G., Brun, J.M., Monnerot, M., Abeni, F., Arnal, C., Arnold, J., ..., \& Zimmermann, J.M. (2000). Evaluation and conservation of European rabbit (Oryctolagus Cuniculus). Genetic resources. First results and Inferences. In: Blasco, A. (ed.). Proceedings of the $7^{\text {th }}$ World Rabbit Congress. Universidad Politécnica de Valencia, Vol. A, pp.281-316.

Brody, S., (1945). Bioenergetics and Growth. New York: Reinhold Publishing, pp. 1-1023. Brun, J.M., \& Ouhayoun, J. (1989). Growth performances and carcass traits in the three strains of rabbits and their two-way crosses. Annales de Zootechnie, 38, 171-179.

Brun, J.M., \& Ouhayoun, J. (1994). Qualités bouchères de laperaux issus d'un croisement diallèle de 3 souches: interaction du type génétique et de la taille de portée d'origine. Annales de Zootechnie, 43, 173-183.

Cartuche, L., Pascual, M., Gómez, E.A., \& Blasco, A. (2014). Economic weights in rabbit meat production. World Rabbit Science 23, 165-177.

Dalle Zotte, A. (2002). Perception of rabbit meat quality and major factors influencing the rabbit: carcass and meat quality. Livestock Production Science, 75, 11-32.

Dalle Zotte, A., Szendrő, K, Gerencsér, Zs, Szendrő, Zs, Cullere, M., Odermatt, M., ..., \& Matics, Zs (2015). Effect of genotype, housing system and hay supplementation on carcass traits and meat quality of growing rabbits. Meat Science, 110, 126-134.

Drouilhet, L., Gilbert, H., Balmisse, E., Ruesche, J., Tircazes, A., Larzul, C., \& Garreau, H. (2013). Genetic parameters for two selection criteria for feed efficiency in rabbits. Journal of Animal Science, 91, 3121-3128. 
Drouilhet, L., Achard, C.S., Zemb, O., Molette, C., Gidenne, T., Larzul C., ..., \& Gilbert, H. (2016). Direct and correlated responses to selection in two lines of rabbits selected for feed efficiency under ad libitum and restricted feeding: I. Production traits and gut microbiota characteristics. Journal of Animal Science, 94, 38-48.

703

704

705

706

707

708

709

710

711

712

713

714

715

716

717

718

719

720

721

722

723

724

725

726

727

728

729

730

731

732

Ferraz, J.B.S., Johnson, R.K., \& Eler, J.P. (1991). Genetic parameters for growth and carcass traits of rabbits. Journal of Applied Rabbit Research, 14, 187-192.

Ferraz, J.B.S., Johnson, R.K., \& Van Vleck, L.D. (1992). Estimation of genetic trends and genetic parameters for reproductive and growth traits of rabbits raised in subtropics with animal models. Journal of Applied Rabbit Research, 15, 131-142.

Garreau, H., Eady, S.J., Hurtaud, J., \& Legarra, A. (2008). Genetic parameters of production traits and resistance to digestive disorders in a commercial rabbit population. In: Xiccato, G., Trocino, A., \& Lukefahr, S. (eds.). Proceedings of the 9th World Rabbit Congress. Fondazione Iniziative Zooprofilattiche e Zootechniche, Verona, Italy, pp. 103-108.

Garreau, H., Gilbert, H., Molette, C., Larzul, C., Balmisse, E., Ruesche, J., ..., \& Drouilhet, L. (2015a). Réponses à la sélection pour deux critères d'efficacité alimentaire chez le lapin. 1. Croissance, ingéré et efficacité alimentaire. In: 16èmes Journées de la Recherche Cunicole, ITAVI, Le Mans, France, pp. 161-164.

Garreau, H., Molette, C., Gilbert, H., Larzul, C., \& Balmisse, E. (2015b). Réponses à la sélection pour deux critères d'efficacité alimentaire chez le lapin. 2. Caractères de carcasse et de qualité de viande. 16èmes Journées de la Recherche Cunicole, ITAVI, Le Mans, France, pp. 169-172.

Garreau, H., Gilbert, H, Molette, C., Larzul, C., Balmisse, E., Ruesche, J., \& SeculaTircazes, A. (2016). Direct and correlated responses to selection in two lines of rabbits selected for feed efficiency under ad ibitum and restricted feeding. In: Lin, Y., Li, F., \& Gidenne, T. (eds). Proceedings of the 11th World Rabbit Congress. Chinese Association of Animal Science and Veterinary Medicine. Qingdao. China. pp. 43-46.

Gasperlin, L., Polak, T., Rajar, A., Skvarea, M., \& Lender, B. (2006). Effect of genotype, age, at slaughter and sex on chemical composition and sensory profile of rabbit meat. World Rabbit Science, 14, 157-166.

Gil, M., Ramírez, J., Pla, M., Ariño, B., Hernández, P., Pascual, M., ..., \& Oliver, M.A. (2006). Effect of selection for growth rate on the ageing of myofibrils, the meat texture properties and the muscle proteolytic potential of longissimus from two groups of rabbits. Meat Science, 72, 121-129. 
Gómez, E.A., Baselga, M., Rafel, O., \& Ramon, J. (1998). Comparison of carcass characteristics in five strains of meat rabbit selected on different traits. Livestock Production Science, 55, 53-64.

Gondret, F., Larzul, C., Combes, S., \& de Rochambeau, H. (2005). Carcass composition, bone mechanical properties, and meat quality traits in relation to growth rate in rabbits. Journal of Animal Science, 83, 1526-1535.

Gyovai, P., Nagy, I., Gerencsér, Zs., Metzger, Sz., Radnai, I., \& Szendrő, Zs. (2008). Genetic parameters and trends of the thigh muscle volume in Pannon White rabbits. In: Xiccato, G., Trocino, A., Lukefahr, S. (eds.). Proceedings of the 9th World Rabbit Congress. Fondazione Iniziative Zooprofilattiche e Zootechniche, Verona, Italy, pp. 115-119.

Gyovai, P., Nagy, I., Gerencsér, Zs., Matics, Zs., Radnai, I., Donkó, T., ..., \& Szendrő, Zs. (2012). Genetic parameters for litter weight, average daily gain and thigh muscle volume measured by in vivo Computer Tomography technique in Pannon White rabbits. Livestock Science, 144, 119-123.

Hernández, P., Aliaga, S., Pla, M., \& Blasco, A. (2004). The effect of selection for growth rate and slaughter age on carcass composition and meat quality traits in rabbits. Journal of Animal Science, 82, 3138-3143.

Hernández, P., Guerrero, L., Ramírez, J., Mekkawy, W., Pla, M., Ariño, B., Ibáñez, N., \& Blasco, A. (2005). A Bayesian approach of the effect of selection for growth rate on sensory meat quality of rabbit. Meat Science, 69, 123-127.

Hernández, P., \& Gondret, F. (2006). Rabbit meat quality. In: Maertens, L., Coudert, P. (eds.). Recent advances in rabbit sciences. ILVO, Melle, Belgium, pp. 269-290.

Hernández, P., Ariño, B., Grimal, A., \& Blasco, A. (2006). Comparison of carcass and meat characteristics of three rabbit lines selected for litter size or growth rate. Meat Science, 73, 645-650.

Hernández, P., Cesari, V., \& Blasco, A. (2008). Effect of genetic rabbit lines on lipid content, lipolytic activities and fatty acid composition of hind leg meat and perirenal fat. Meat Science, 78, 485-491.

Hulot, F., \& Ouhayoun, J. (1999). Muscular pH and related traits in rabbits: a review. World Rabbit Science, 7, 15-36.

Kennedy, B.W., Van der Werf, J.H.J., \& Meuwissen, T.H.E. (1993). Genetic and Statistical Properties of Residual Feed Intake. Journal of Animal Science, 71, 32393250 . 
Koch, R.M., Swiger, L.A., Chambers, D., \& Gregory, K.E. (1963). Efficiency of feed use in beef cattle. Journal of Animal Science, 22, 486-494.

Krogmeier, D., Dzapo, V., \& Mao, I.L. (1994). Additive and maternal effects of postweaning growth and carcass traits in rabbits. Journal of Animal Breeding and Genetics, 111, 289-297.

Larzul, C., \& de Rochambeau, H. (2005). Selection for residual feed consumption in the rabbit. Livestock Production Science, 95, 67-72.

Larzul, C., Gondret, F., Combes, S., \& de Rochambeau, H. (2005). Divergent selection on 63-day body weight in the rabbit: response on growth, carcass and muscle traits. Genetics Selection Evolution, 37, 105-122.

Lebas, F., Coudert, P., Rochambeau, H., \& Thébault, R. G. (1997). The rabbit: husbandry, health and production. Rome: FAO.

Lenoir, G., \& Morien, F. (2015). Intérét de l'évaluation par échographie des caracteristiques de carcasse pour la selection du lapin de chair. 16èmes Journées de la Recherche Cunicole, ITAVI, Le Mans, France, pp. 177-180.

Lenoir G., \& Morien F. (2016). Estimation of genetic parameters for carcass traits evaluated by in vivo real-time ultrasonography in meat rabbit breeding. In: Lin, Y., Li, F., \& Gidenne, T. (eds.). Proceedings of the 11th World Rabbit Congress. Chinese Association of Animal Science and Veterinary Medicine. Qingdao. China.. pp. 71-75.

Lukefahr, S.D., Hohenboken, W.D., Cheeke, P.R ., Patton, N.M., \& Kennick, W.H. (1982). Carcass and meat characteristics of Flemish Giant and New Zealand White purebred and Terminal-Cross rabbits. Journal of Animal Science, 54, 1169-1174.

Lukefahr, S.D., Odi, H.B., \& Atakora, J.K.A. (1996). Mass selection for 70-day body weight in rabbits. Journal of Animal Science, 74, 1481-1489.

Martínez-Álvaro, M., Hernández, P., \& Blasco, A. (2016a). Divergent selection on intramuscular fat in rabbits: Responses to selection and genetic parameters. Journal of Animal Science, 94, 4993-5003.

Martínez-Álvaro, M., Penalba, V., Hernández, P., \& Blasco, A. (2016b). Effect of divergent selection for intramuscular fat on sensory traits and instrumental texture in rabbit meat. Journal of Animal Science, 94, 5137-5143. rabbit lines divergently selected for intramuscular fat. Journal of Animal Science, 95, 2576-2584. 
Martínez-Alvaro, M., Hernández, P., Agha, S., \& Blasco, A. (2018a). Correlated responses to selection for intramuscular fat in several muscles in rabbits. Meat Science, 139, 187191.

Martínez-Álvaro, M., Paucar, Y., Satué, K., Blasco, A., \& Hernández, P. (2018b). Liver metabolism traits in two rabbit lines divergently selected for intramuscular fat. Animal. In press.

Matics, Zs., Nagy, I., Gerencsér, Zs., Radnai, I., Gyovai, P., Donkó, T., ..., \& Szendrő, Zs., (2014). Pannon breeding program at Kaposvár University. World Rabbit Science, 22, 287-300.

McCarthy, J.C. (1980). Morphological and physiological effects of selection for growth

Martínez-Álvaro, M., Blasco, A., \& Hernández, P. (2018c). Genetic parameters and correlated responses to selection for intramuscular fat on fatty acid composition of rabbit meat. Animal. In press.

rate in mice. In: Robertson, A. (ed.). Selection experiments in Laboratory and domestic animals. Commonwealth Agricultural Bureau. Slough, UK. pp. 100-109.

Metzger, Sz., Odermatt, M., Szendrő, Zs., Mohaupt, M., Romvári, R., Makai, A., ..., \& Horn, P. (2006a). A study of the carcass traits of different rabbit genotypes. World Rabbit Science, 14, 107-114.

Metzger, Sz., Odermatt, M., Szendrő, Zs., Mohaupt, M., Romvári, R., Makai, A., ..., \& Sipos, L. (2006b). Comparison of carcass traits and meat quality of Hyplus hybrid, purebred Pannon White rabbits and their crossbreds. Archiv Tierzucht, 49, 389-399. Molette, C., Gilbert, H., Larzul, C., Balmisse, E., Ruesche, J., Manse, M,..., \& Drouilhet, L. (2016). Direct and correlated responses to selection in two lines of rabbits selected for feed efficiency under ad libitum and restricted feeding: II. Carcass and meat quality. Journal of Animal Science, 94, 49-57.

Moura, A., Kaps, M., Vogt, D.W., \& Lamberson, W.R. (1997). Two-way selection for daily gain and feed conversion in a composite rabbit population. Journal of Animal Science, 75, 2344-2349.

Nagy, I., Ibañez, N., Mekkawy, W., Metzger, Sz., Horn, P., \& Szendrö, Zs. (2006). Genetic parameters of growth and in vivo computerized tomography based carcass traits in Pannon White rabbits. Livestock Science, 104, 46-52.

Nagy, I., Gyovai, P., Radnai, I., Matics, Zs., Gerencsér, Zs., Donkó, T., \& Szendrő, Zs. (2010). Genetic parameters of growth in vivo CT based and slaughter traits in Pannon white rabbits. In: Erhardt, G. (ed.). Proceedings of the 9th World Congress on Genetics 

Applied to Livestock Production. Event lab. GmbH, Leipzig, Germany, CD Com. No. 341.

Nagy, I., Gyovai, P., Radnai, I., Nagyné Kiszlinger, H., Farkas, J., \& Szendrő, Zs. (2013). Genetic parameters, genetic trends and inbreeding depression of growth and carcass traits in Pannon terminal line rabbits. Archiv Tierzucht, 56, 191-199.

Niedzwiadek, S., Fijal, J., \& Bielanski, P. (1992). Progress in area of reproduction in a specialized line of rabbits. In: Cheeke, P.R. (ed.). Proceedings of the $5^{\text {th }}$ World Rabbit Congress. WRSA, Corvallis, Oregon, USA. Vol. A, pp. 314-321.

Ouhayoun, J., \& Rouvier, R. (1973). Composition corporelle e degré de maturité en poids de lapereaux de plusieurs génotypes. lères Journées de recherches avicoles et cunicoles. ITAVI, Paris. France. pp. 85-88.

Ouhayoun, J., \& Poujardieu, B. (1978). Comparative study of rabbit crossbreeding, between-breed and within-breed relationships between traits of the terminal products. 2èmes Journées de la recherche cunicole en France. Association Scientifique Française de Cuniculture. Toulouse, France. Comm. 25, pp. 1-3.

Ouyed, A., Rivest, J., \& Brun, J.M. (2011). Heterosis, direct and maternal additive effects on rabbit growth and carcass traits from a Canadian experiment. World Rabbit Science, 19, 31-41.

Ozimba, C.E., \& Lukefahr, S.D. (1991). Evaluation of purebred and crossbred rabbits for carcass merit. Journal of Animal Science, 69, 2371-2378.

Pascual, M., \& Pla, M. (2007). Changes in carcass composition and meat quality when selecting rabbits for growth rate. Meat Science, 77, 474-481.

Pascual, M., Pla, M., \& Blasco, A. (2008). Effect of selection for growth rate on relative growth in rabbits. Journal of Animal Science, 86, 3409-3417.

Pascual, M., Calle, E.W., \& Blasco, A. (2015). Comparison of degrees of maturity of rabbit lines selected for different traits. World Rabbit Science, 23, 155-161.

Pearson, K. (1897). Mathematical Contributions to the Theory of Evolution. On a Form of Spurious Correlation which may arise when Indices are used in the Measurement of Organs. Proceedings of the Royal Society of London, 60, 489-498.

Piles, M., Blasco, A., \& Pla, M. (2000). The effect of selection for growth rate on carcass composition and meat characteristics of rabbits. Meat Science, 54, 347-355.

Piles, M., \& Blasco, A. (2003). Response to selection for growth rate in rabbits estimated by using a control cryopreserved population. World Rabbit Science, 11, 53 - 62 
867 Piles, M., Gomez, E., Rafel. O., Ramon, J., \& Blasco, A. (2004). Elliptical selection experiment for the estimation of genetic parameters of the growth rate and feed conversion ratio in rabbits. Journal of Animal Science, 82, 654-660.

Piles, M., Garcia-Tomas, M., Rafel, O., Ramon, J., Ibanez-Escriche, N., \& Varona, L. (2007). Individual efficiency for the use of feed resources in rabbits. Journal of Animal Science, 85, 2846-2853.

Piles, M., Davi, I., Ramon, J., Canario, L., Rafel, O., Pascual, M., Ragab, M., \& Sánchez, J.P. (2017). Interaction of direct and social genetic effects with feeding regime in growing rabbits. Genetics Selection Evolution, 49, 58.

Pla, M., Hernández, P., \& Blasco, A. (1996). Carcass composition and meat characteristics of two rabbit breeds of different degrees of maturity. Meat Science, 44, 85-92.

Pla, M., Guerrero, L., Guardia, D., Olivier, M.A., \& Blasco, A. (1998). Carcass characteristics and meat quality of rabbit lines selected for different objectives: I. Between lines comparison. Livestock Production Science, 54, 115-123.

Prayaga, K.C., \& Eady, S. (2000). Rabbit farming for meat production in Australia: Preliminary estimates of economic values for production traits. Asian-Australian Journal of Animal Sciences, 13, 357-359.

Prunier, A., Heinonen, M., \& Quesnel, H. (2010). High physiological demands in intensively raised pigs: Impact on health and welfare. Animal, 4, 886-898.

Ramírez, J.A., Oliver, M.A., Pla, M., Guerrero, L., Ariño, B., Blasco, A., Pascual, M., \& Gil, M. (2004). Effect of selection for growth rate on biochemical, quality and texture characteristics of meat from rabbits. Meat Science, 67, 617-624.

Ramírez, J.A., Díaz, I., Pla, M., Gil, M., Blasco, A., \& Oliver, M.A. (2005). Fatty acid composition of leg meat and perirenal fat of two groups of rabbits selected by growth rate. Food Chemistry, 90, 251-256.

Rochambeau, H., de la Fuente, L.F., Rouvier, R., \& Ouhayoun, J., (1989). Sélection sur la vitesse de croissance post-sevrage chez le lapin. Genetics Selection Evolution, 21, $527-$ 546.

Rochambeau, H., Retailleau, B., Poivey, J.P., \& Allain, D. (1994). Selection pour le poids a 70 jours chez le lapin. Gèmes Jourmées de la Recherche Cunicole en France. ITAVI, La Rochelle, France. Vol. 1, pp. 235-240.

Rouvier, R. (1970). Variabilité génétique du rendement a l'abattage et de la composition anatomique de lapins de trois races. Annales de génétique et de sélection animale, 2, 325-346. 
901

902

903

904

905

906

907

908

909

910

911

912

913

914

915

916

917

918

919

920

921

922

923

924

925

926

927

928

929

930

931

932

933

934

Smith, C. (1984). Rates of genetic change in farm animals. Journal of Agricultural Research and Development, 1, 79-85.

Szendrő, Zs., Romvári, R., Horn, P., Radnai, I., Bíró-Németh, E., \& Milisits, G. (1996). Two-way selection for carcass traits by computerised tomography. In: Lebas, F. (ed.). Proceedings of the 6th World Rabbit Congress. Association scientifique française de cuniculture, Toulouse, France, Vol. 2. pp. 371-375.

Szendrő, Zs., Matics, Zs., Gerencsér, Zs., Radnai, I., Lengyel, M., Nagy, I., Riovanto, R., \& Dalle Zotte, A. (2009). Effect of adult weight and CT based selection on carcass traits of growing rabbits. Italian Journal of Animal Science, 8, 240-242.

Szendrö, Zs., Matics, Zs., Gerencsér, Zs., Nagy, I., Lengyel, M., Horn, P., \& Dalle Zotte, A. (2010). Effect of dam and sire genotypes on productive and carcass traits of rabbits. Journal of Animal Science, 88, 533-543.

Szendrő, Zs., Metzger, Sz., Nagy, I., Szabó, A., Petrási, Zs., Donkó, T., \& Horn, P. (2012). Effect of divergent selection for the Computer Tomography measured thigh muscle volume on productive and carcass traits of growing rabbits. Livestock Science, 149, 167-172.

Taylor, St C. (1965). A relation between mature weight and time taken to mature in mammals. Animal. Production, 7, 203-220.

Taylor, St. C. S. (1980). Genetic size-scaling rules in animal growth. Animal Production, $30,161$.

Taylor, St. C., (1985). Use of genetic size-scaling in evaluation of animal growth, Journal of Animal Science, 61, Suppl. 2: 118-143.

Taylor, St. C. (2009). Genetic size scaling. In: Rauw, W.M. (ed.). Resource allocation theory applied to farm animal production. CABI. Wallingford. UK, pp. 147-168.

Webb, A.J. (1989). Genetics of food intake in the pig. In: Forbes, J.M., Varley, M.A., Lawrence, T.L.J. (ed.). The Voluntary Food Intake of Pigs. British Society of Animal Production, Midlothian, UK, pp. 41-50.

Whittemore, C.T. (1987). Elements of pig science. Longman. Harlow, UK, pp. 1-192.

Zomeño, C., Hernández, P., \& Blasco, A. (2013a). Divergent selection for intramuscular fat content in rabbits. I. Direct response to selection. Journal of Animal Science, 91, 4526-4531.

Zomeño, C., Hernández, P., \& Blasco, A. (2013b). Divergent selection for intramuscular fat content in rabbits. II. Correlated responses in meat characteristics. Journal of Animal Science, 91, 4532-4539. 
